Ю.А.Беспятых ${ }^{1}$, Е.А.Шитиков ${ }^{1}$, Д.В.Зименков ${ }^{2}$, Е.В.Кулагина ${ }^{2}$, Д.А.Грядунов ${ }^{2}$, Е.Ю.Носова ${ }^{3}$, А.А.Букатина ${ }^{3}$, М.В.Шульгина ${ }^{4}$, В.Ю.Журавлев ${ }^{4}$, Е.Н.Ильина ${ }^{1}$

Определение лекарственной устойчивости и генотипирование клинических штаммов Mycobacterium tuberculosis при помощи экспериментального набора "ТБ-ТЕСТ"

1 - НИИ физико-химической медицины ФМБА России: 119435, Москва, ул. Малая Пироговская, 1а;

2 - ФГБУН "Институт молекулярной биологии им. Энгельгардта" РАН: 119991, Москва, ул. Вавилова, 32;

3 - Московский городской научно-практический центр борьбы с туберкулезом: 107014, Москва, ул. Стромынка, 10;

4 - НИИ фтизиопульмонологии: 191036, Санкт-Петербург, Лиговский пр., 2-4

Yu.A.Bespyatykh, E.A.Shitikov, D.V.Zimenkov, E.V.Kulagina, D.A.Gryadunov, E.Yu.Nosova, A.A.Bukatina, M.V.Shulgina, V.Yu.Zhuravlev, E.N.Ilyina

\title{
Identification of drug resistance and genotyping of clinical isolates of Mycobacterium tuberculosis using the TB-TEST
}

\begin{abstract}
Summary
Drug resistance and genotype of Mycobacterium tuberculosis were analyzed in 266 DNA samples isolated from clinical material of patients with TB using an experimental test system TB-TEST. This method is bases on oligonucleotide microarray technology and allows determination most prevalent in Russia genotypes of M. tuberculosis and genomic mutations responsible for drug resistance to the main medications used for treatment of TB: rifampicin, isoniazid, ethambutol, fluoroquinolones, aminoglycosides, and capreomycin. As a result, drug resistance profiles and genotypes were identified for all samples. The test results were highly related to results of conventional microbiological tests. The TB-TEST could be used as a preferred laboratory method for diagnosis of TB.

Key words: Mycobacterium tuberculosis, TB-TEST, biochip, drug resistance, genotyping.
\end{abstract}

\section{Резюме}

Проведен анализ лекарственной устойчивости 266 образцов геномной ДНК Mycobacterium tuberculosis с использованием экспериментального набора "ТБ-ТЕСТ". Этот метод основан на применении технологии олигонуклеотидных биочипов и позволяет определять наиболее распространенные в России генотипы патогена, а также мутации, ответственные за формирование резистентности к основным препаратам, применяемым для лечения туберкулеза, - рифампицину, изониазиду, этамбутолу, фторхинолонам, аминогликозидам и капреомицину. В результате были получены профили резистентности и определены генотипы для всех образцов. Тестируемый метод показал хорошую корреляцию результатов с данными классических микробиологических тестов. Разработанная система "ТБ-ТЕСТ" является приоритетной для использования в клинической лабораторной диагностике.

Ключевые слова: Mycobacterium tuberculosis, ТБ-ТЕСТ, биочип, лекарственная устойчивость, генотипирование.

В России туберкулез является одной из наиболее значимых проблем здравоохранения и социального развития страны. В настоящее время можно говорить о наметившейся тенденции к снижению заболеваемости, которая, однако, продолжает оставаться на достаточно высоком уровне. Только за последний год, по данным Всемирной организации здравоохранения, в стране были выявлены около 90 тыс. вновь заболевших [1]. Значительную роль в обострении ситуации с туберкулезом играет появление и все большее распространение микобактерий, устойчивых к лекарственным препаратам. Наибольшую опасность представляют изоляты Mycobacterium tuberculosis (МБТ), обладающие множественной и широкой лекарственной устойчивостью (МЛУ и ШЛУ соот- ветственно). К МЛУ относят штаммы, одновременно устойчивые к изониазиду и рифампицину; к ШЛУ к изониазиду, рифампицину, фторхинолонам и к 1 из группы инъекционных препаратов: канамицину или / и амикацину, или / и капреомицину [2].

Туберкулез, вызванный формами МБТ с МЛУ и ШЛУ, сопровождается тяжелыми деструктивными процессами и носит прогрессирующий характер. Лечение таких пациентов сопряжено с рядом трудностей и зачастую приводит к развитию хронических и неизлечимых форм заболевания с неблагоприятным прогнозом [3]. По данным Центрального НИИ организации и информатизации здравоохранения в России, > 41 \% впервые выявленных случаев туберкулеза вызываются штаммами с МЛУ-фенотипом. 
В свою очередь, среди всех МЛУ-фенотипов $30 \%$ составляют штаммы с ШЛУ.

Другой актуальной проблемой на сегодня является определение структуры популяции МБТ. Предварительное определение генотипа имеет большое значение для эпидемиологического мониторинга. Показано, что штаммы Beijing превалируют в структуре популяции возбудителя туберкулеза в России и ассоциированы с лекарственной устойчивостью (ЛУ) [4]. В свою очередь, кластер В0 / W148 является наиболее распространенным в России вариантом генотипа Beijing $[5,6]$. Представители этого кластера преобладают у больных тяжелыми формами туберкулеза и демонстрируют высокую вирулентность [79] и трансмиссивность [10], ассоциацию с ЛУ [5, $6,11]$. Другими наиболее часто встречающимися на территории России генотипами являются Ural и LAM.

Очевидно, что в сложившейся ситуации весьма актуальны исследования, направленные на решение проблемы своевременного выявления МЛУ- и ШЛУформ для ранней коррекции противотуберкулезной терапии, а также на проведение адекватных противоэпидемических мероприятий, ориентированных на предупреждение распространения штаммов микобактерий.

Применяемые на сегодняшний день микробиологические методы диагностики туберкулеза весьма трудоемки, дороги, плохо поддаются стандартизации и занимают в исполнении от 3 нед. до 3 мес. В этом направлении широкие перспективы и возможности открывают современные достижения молекулярной биологии. Принципиально новым подходом для молекулярной диагностики МБТ является технология гидрогелевых биочипов, разработанная в Институте молекулярной биологии им. Энгельгардта РАН. Данная технология уже хорошо зарекомендовала себя в клинической практике и используется для типирования МБТ, вирусов гепатита С, оспы и гриппа, а также для анализа генетических изменений у человека при различных заболеваниях [12]. В настоящее время для определения ЛУ МБТ используются 2 тест-системы. Тест-система "ТБ-Биочип-1" позволяет выявить мутации, ответственные за устойчивость к рифампицину и изониазиду [13]. Вторая тест-система направлена на определение устойчивости к фторхинолонам, аминогликозидам и капреомицину [14].

Цель настоящего исследования - проведение лабораторной апробации нового экспериментального набора "ТБ-ТЕСТ", основанного на использовании олигонуклеотидных микрочипов и предназначенного для определения ЛУ и генотипирования M. tuberculosis.

\section{Материалы и методы}

Клинические образцы. В исследование было включено 266 образцов геномной ДНК МБТ из охарактеризованной лабораторной коллекции НИИ физикохимической медицины. Данная выборка являлась эпидемиологически не связанной и включала 46 образцов геномной ДНК, выделенных из мокроты и бронхиальных смывов пациентов с продуктивным туберкулезом легких, и 220 образцов ДНК, выделенных из чистых культур МБТ, полученных в ходе бактериологического тестирования. Бактериологическое исследование культур МБТ на чувствительность к противотуберкулезным препаратам 1-го и 2-го ряда было проведено методом абсолютных концентраций и на приборе Bactec MGIT 960. В качестве контрольного использовали музейный лабораторный штамм H37Rv.

Генотипирование и тестирование маркеров ЛУ. Обнаружение генетических маркеров ЛУ и генотипирования МБТ проводилось с использованием экспериментального набора "ТБ-ТЕСТ", разработанного в рамках Государственного контракта № 16.522.11. 2003 на тему: "Разработка и выпуск опытных образцов тест-системы для обнаружения лекарственноустойчивого туберкулеза с учетом особенностей геномной организации эндемичных для России штаммов". Данный набор реализует принцип гибридизации на гидрогелевых биочипах. Геномная ДНК клинических штаммов использовалась для постановки одностадийной мультиплексной полимеразной цепной реакции, в ходе которой получались флуоресцентно-меченные фрагменты ДНК. Затем полученные фрагменты гибридизовались на биочипе со специфическими зондами при $37{ }^{\circ} \mathrm{C}$. Биочип разбит на группы, определяющие принадлежность к генотипу, устойчивость к противотуберкулезным препаратам (см. рисунок). Отдельную группу составляет зонд IS, специфичный к фрагменту инсерционного элемента IS6110, определяющего принадлежность к микобактериям туберкулезного комплекса. Завершающим этапом являлась оценка полученных результатов на универсальном аппаратно-программном комплексе (УАПК) для анализа биочипов. Программное обеспечение ImaGeWare, входящее в состав УАПК, позволяет сравнить флуоресцентные сигналы в ячейках и определить, где образовались совершенные гибридизационные комплексы.

Параметры диагностической специфичности (Sp) и чувствительности (Sn) рассчитывались при помощи следующих формул:

$$
\begin{aligned}
& S p=T n /(T n+F p) \times 100 \%, \\
& S n=T p /(T p+F n) \times 100 \%,
\end{aligned}
$$

где Тр - истинно положительный результат, Tn - истинно отрицательный результат, Fp - ложноположительный результат, Fn - ложноотрицательный результат.

\section{Результаты и обсуждение}

Для апробации метода была использована лабораторная коллекция из 266 образцов геномной ДНК M. tuberculosis. В данную коллекцию были включены 46 фенотипически не охарактеризованных образцов тотальной ДНК, выделенной из мокроты и бронхиальных смывов пациентов с продуктивным туберку- 


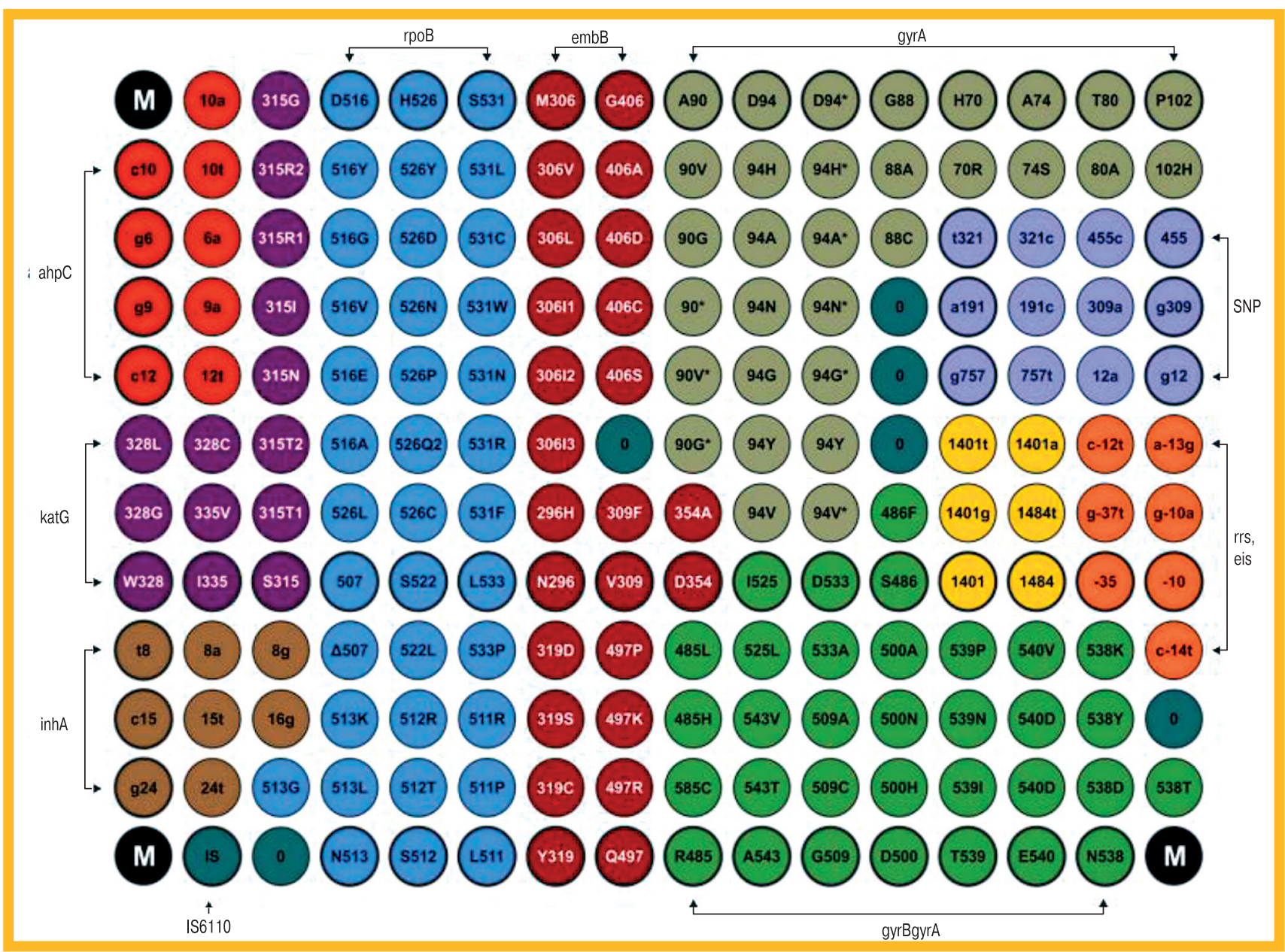

Рисунок. Схема биочипа, входящего в состав набора "ТБ-ТЕСТ" и содержащего иммобилизованные олигонуклеотидные зонды. Ячейки с индексом '0' не содержат олигонуклеотидов и выполняют роль отрицательного контроля. Ячейки с индексом 'М' содержат флуоресцентный маркер для автоматической обработки гибридизационной картины биочипа

лезом легких, и 220 образцов ДНК, выделенных из чистых культур МБТ, для которых были установлены профили антибиотикорезистентности. По данным микробиологических тестов, в анализируемой выборке 41 (41 / 220; 18,6 \%) образец был чувствителен к противотуберкулезным препаратам; 13 (13 / 220; 5,9 \%) образцов были монорезистентными; 5 (5 / 220; 2,3 \%) - полирезистентными; 112 (112 / 220; 50,9 \%) имели МЛУ-фенотип; 49 (49 / 220; 22,3 \%) - ШЛУфенотип.

При использовании экспериментального набора "ТБ-ТЕСТ" были получены результаты для $100 \%$ (220 / 220) образцов, выделенных из чистой культуры МБТ, и 98 \% (45 / 46) образцов, выделенных из мокроты и бронхиальных смывов. Согласно результатам тестирования бактериологически охарактеризованной группы $(n=220)$, к фенотипической категории "чувствительные" были отнесены 38 (38 / 220; 17,3\%) образцов, 12 образцов (12 / 220; 5,5 \%) в данной выборке были определены как монорезистентные, 8 (8 / 220; 3,6 \%) - полирезистентные, 109 (109 / 220; 49,5 \%) - МЛУ и 53 (53 / 220; 24,1 \%) - ШЛУ (табл. 1).

Среди чувствительных изолятов достоверно было идентифицировано 90,2 \% (37 / 41) образца: 1 образец был оценен как ложноположительный, поскольку по бактериологическим данным он был монорезистентен к рифампицину; 4 образца оказались ложноотрицательными.

Среди монорезистентных изолятов было идентифицировано 12 / 13 образцов, 1 образец был ложно-

Таблица 1

Сравнение результатов определения ЛУ классическим методом и с помощью тест-системы "ТБ-ТЕСТ" и расчет диагностической чувствительности и спещифичности

\begin{tabular}{|l|c|c|c|c|}
\hline \multicolumn{1}{|c|}{ Фенотипическая категория } & $\begin{array}{c}\text { Бактериологическое } \\
\text { тестирование, } n\end{array}$ & "ТБ-ТЕСТ", $n$ & $\begin{array}{c}\text { Чувствительность } \\
\text { "ТБ-ТЕСТ", \% }\end{array}$ & $\begin{array}{c}\text { Специфичность } \\
\text { "ТБ-ТЕСТ", \% }\end{array}$ \\
\hline Чувствительные & 41 & 38 & 90 & 99 \\
\hline Монорезистентные & 13 & 12 & 92 & 100 \\
Полирезистентные & 5 & 8 & 100 & 99 \\
\hline Млу & 112 & 109 & 92 & 94 \\
Шлу & 49 & 53 & 94 & 95 \\
\hline
\end{tabular}


отрицательным. Среди полирезистентных изолятов достоверно были идентифицированы 5 / 5 образцов. Для 3 образцов был получен ложноположительный результат.

Диагностическая специфичность и чувствительность обнаружения МЛУ- и ШЛУ-фенотипов составила 92; 94 \% и 95; $94 \%$ соответственно. Стоит отметить, что при сопоставлении данных бактериологического и генетического тестирования видно некоторое комплементарное перераспределение штаммов, отнесенных к категориям МЛУ и ШЛУ. По данным генетического тестирования, наблюдается увеличение числа штаммов, отнесенных к ШЛУ за счет уменьшения МЛУ. Возможно, это объективный процесс, объясняемый проблемами в оценке ЛУ препаратов 2-й линии.

Экспериментальный набор "ТБ-ТЕСТ" позволяет выявлять суммарно 114 генетических детерминант ЛУ: из них 28 мутаций - в гене rpoB, ответственных за устойчивость к рифампицину; 11 мутаций - в гене katG, по 5 - в inhA и ahpC, приводящих к устойчивости к изониазиду; 18 - в еmbВ, ответственных за устойчивость к этамбутолу; 15 - в gyrA; 23 - в gyrB, ответственных за устойчивость к фторхинолонам; 4 - в rrs; 5 - в eis, приводящих к устойчивости к аминогликозидам и капреомицину.

Согласно результатам "ТБ-ТЕСТ", в гене гроВ рифампицин-резистентных штаммов МБТ чаще всего встречались мутации в кодонах 531 (78,3 \%), 516 $(11,6 \%)$ и $526(7,2 \%)$. Наиболее часто детектировали замену типа Ser531>Leu (72,5\%).

Замены, приводящие к резистентности к изониазиду, были детектированы в генах katG в 96,5 \% случаев, inhA - в 24,7 \%, ahpC - 4,1\%. В данном случае превалирующей была мутация в KatG Ser315Thr (87\%).

В гене етbВ, ассоциированном с резистентностью к этамбутолу, чаще всего присутствовала мутация в кодоне 306, приводящая к замене типа Met306Val (68,8 \%). Следует отметить, данная мутация встретилась и у 5 чувствительных образцов, что согласуются с данными мировой литературы $[15,16]$.

Среди фторхинолон-резистентных образцов мутации по кодонам 90, 91, 94 гена gyrA были найдены в 77,6 \% (59 / 76). Резистентность к аминогликазидам по большей части была связана с мутацией в ге- не rrs a1401g (47,2 \%) и мутацией g(-10)а в промоторной области гена еis $(18,5 \%)$.

Кроме того, в состав экспериментального набора "ТБ-ТЕСТ" включен блок, позволяющий устанавливать принадлежность МБТ к наиболее распространенным на территории России генотипам. Данный блок содержит 12 ячеек, определяющих генотипспецифические SNPs. Следует отметить, что соответствующие SNPs были идентифицированы в ходе анализа полногеномного секвенирования 40 эндемичных для России штаммов МБТ (GenBank accession number: SRA061654). В случае установления "дикого" типа по полиморфизму Rv0557_321T>C штамм относился к европейско-американскому типу с дальнейшей идентификацией семейств LAM (по полиморфизму Rv0129c_309G>A), либо Ural (по полиморфизму Rv1811_12G>A). При выявлении полиморфизма Rv0557_321T>C штамм относился K азиатскому типу и при наличии полиморфизма Rv2629_191A>C определялся генотип Beijing. При выявлении замены Rv0118c_757G > Т в гене охсА устанавливалась принадлежность штамма к семейству B0/W148 генотипа Beijing. Таким образом, на 1 чипе осуществляется как идентификация генетических детерминант МЛУ и ШЛУ форм туберкулеза, так и определение наиболее распространенных на территории России генотипов M. tuberculosis.

Согласно полученным данным, в коллекции преобладали штаммы с генотипом Beijing (54,5\%), в меньшей степени представлены генотипы Ural (7 \%), LAM (6,4 \%) и штаммы, относящиеся к европейско-американскому типу (32,1\%). Из всех штаммов, принадлежащих к генотипу Beijing, $30 \%$ относились к семейству В0/W148. Доля образцов, относившихся к генотипу Beijing и имевшая МЛУ / ШЛУ фенотип, составила 67,4\%. Все образцы (100\%) в исследуемой выборке, идентифицированные как генотип В0/W148, имели МЛУ- и ШЛУ-формы, что подтверждает значимость данного семейства. Для остальных генотипов подобные закономерности не выявлены.

Для определения возможности использования системы "ТБ-ТЕСТ" в клинической диагностике дополнительно было протестировано 46 образцов микобактериальной ДНК, выделенной из мокроты и бронхиальных смывов больных туберкулезом легких.

Таблица 2

Обобщенные результаты исследования маркеров ЛУ и генотипирования 265 образцов геномной ДНК M. tuberculosis, выделенной из чистой БК и КМ (мокроты и бронхиальных смывов)

\begin{tabular}{|c|c|c|c|c|c|c|c|c|c|c|c|c|}
\hline \multirow{3}{*}{$\begin{array}{c}\text { Установленный } \\
\text { фенотип }\end{array}$} & \multicolumn{12}{|c|}{ Генотипы, $n$} \\
\hline & \multicolumn{2}{|c|}{ B0 / W148 Beijing } & \multicolumn{2}{|c|}{ Другие Beijing } & \multicolumn{2}{|c|}{ LAM } & \multicolumn{2}{|c|}{ Ural } & \multicolumn{2}{|c|}{ остальные } & \multicolumn{2}{|c|}{ Всего } \\
\hline & БК & KM & БК & KM & БК & KM & БК & KM & БК & KM & БК & KM \\
\hline Чувствительные & 0 & 0 & 8 & 1 & 2 & 0 & 3 & 0 & 28 & 2 & 41 & 3 \\
\hline Монорезистентные & 0 & 0 & 4 & 0 & 2 & 0 & 1 & 0 & 6 & 0 & 13 & 0 \\
\hline Полирезистентные & 1 & 0 & 2 & 0 & 1 & 0 & 0 & 0 & 1 & 0 & 5 & 0 \\
\hline млу & 23 & 2 & 46 & 0 & 4 & 1 & 9 & 0 & 30 & 1 & 112 & 4 \\
\hline шлу & 12 & 12 & 22 & 6 & 5 & 8 & 2 & 5 & 8 & 7 & 49 & 38 \\
\hline Всего & 36 & 14 & 82 & 7 & 14 & 9 & 15 & 5 & 73 & 10 & 220 & 45 \\
\hline
\end{tabular}

Примечание: БК - бактериальная культура; КМ - клинический материал. 
Для 45 образцов были идентифицированы маркеры резистентности и принадлежность к тому или иному генотипу. В 1 образце, выделенном из бронхиальных смывов, ДНК отсутствовала. В анализируемой выборке было обнаружено 3 (6,7 \%) чувствительных образца, 42 (93,3 \%) образца имели МЛУ-фенотип, из них 90,5 \% - ШЛУ. Также в данной выборке преобладал генотип Beijing (58,3 \%). Обобщенные результаты исследования бактериальных культур и клинического материала представлены в табл. 2.

Таким образом, данный тест является экспрессметодом, позволяющим проводить раннюю диагностику МБТ в клиническом материале, не дожидаясь получения чистой культуры. Представленная технология для определения ЛУ M. tuberculosis обладает высокой производительностью, эффективностью, экономичностью и может стать приоритетной для использования в клинической лабораторной диагностике. Использование данной технологии позволит в перспективе осуществить динамическое наблюдение путей переноса возбудителя туберкулеза в регионе, улучшить систему эпиднадзора за туберкулезом и контроль эффективности лечения.

\section{Заключение}

Таким образом, экспериментальная тест-система "ТБ-ТЕСТ" отвечает требованиям фтизиопульмонологии и может найти широкое применение для исследования МБТ. Данная технология может быть использована как вспомогательный метод раннего выявления резистентных форм МБТ, что будет способствовать быстрому выбору правильной стратегии лечения и предотвращению распространения МЛУ / ШЛУ-форм.

Работа поддержана государственным контрактом с Министерством образования и науки РФ № 16.522.11.2003 и программой фундаментальных исследований Президиума РАН "Молекулярная и клеточная биология".

\section{Литература}

1. Бюллетень ВОЗ. Европейское региональное бюро BO3; 2012: 90. http://apps.who.int/iris/bitstream/10665/ 83803/1/9789244505113_rus.pdf

2. CDC. Notice to readers: Revised Definition of extensively drug-resistant tuberc. Morbid. Mortal. Wkly Rep. 2006; 55 (43): 1176.

3. Zignol M., Hosseini M. S., Wright A. et al. Global incidence of multidrug-resistant tuberculosis. Infect. Dis. 2006; 194: 479-485.

4. Нарвская О.В., Мокроусов И.В., Оттен Т.Ф. и др. Генетическое маркирование полирезистентных штаммов Mycobacterium tuberculosis, выделенных на Северо-Западе России. Пробл. туб. 1999; 3: 39-41.

5. Нарвская О.В. Геномный полиморфизм Mycobacterium tuberculosis и его роль в эпидемическом процессе: Автореф. дис. ... д-ра мед. наук. СПб.; 2003.

6. Toungoussova O., Sandven P., Mariandyshev A. et al. Spread of drug-resistant Mycobacterium tuberculosis strains of the Beijing genotype in the Archangel Oblast, Russia. J. Clin. Microbiol 2002; 40: 1930-1937.
7. Вишневский Б.И., Нарвская О.В., Васильева С.Н. и др. Вирулентность микобактерий туберкулеза. Пробл. туб. 2002; 10: 33-36.

8. Черноусова Л.Н., Андреевская С.Н., Смирнова Т.Г. и др. Биологические свойства штаммов M. tuberculosis кластера W. Пробл. туб. и бол. легких 2008; 10: 45-50.

9. Lopez B., Aguilar D., Orozco H. et al. A marked difference in pathogenesis and immune response induced by different Mycobacterium tuberculosis genotypes. Clin. Exp. Immunol. 2003; 133: 37.

10. Mokrousov I., Narvskaya O., Vyazovaya A. et al. Mycobacterium tuberculosis Beijing Genotype in Russia: in Search of Informative Variable-Number Tandem-Repeat Loci. J Clin Microbiol 2008; 46: 3576-3584.

11. Kruuner A., Hoffner S. E., Sillastu H. et al. Spread of drugresistant pulmonary tuberculosis in Estonia. J. Clin. Microbiol. 2001; 39: 3339-3345.

12. Gryadunov D., Dementieva E., Mikhailovich V. et al. Gelbased microarrays in clinical diagnostics in Russia. Exp. Rev. Mol. Diagn. 2011; 11 (8): 839-853

13. Gryadunov D., Mikhailovich V., Lapa S. et al. Evaluation of hybridisation on oligonucleotide microarrays for analysis of drug-resistant Mycobacterium tuberculosis. Clin. Microbiol. Infect. 2005; 11: 531-539.

14. Zimenkov D.V., Antonova O.V., Kuz'min A.V. et al. Detection of second-line drug resistance in Mycobacterium tuberculosis using oligonucleotide microarrays. BMC Infect. Dis. 2013; 13: 240.

15. Mokrousov I., Otten T., Vyshnevskiy B. et al. Detection of embB306 mutations in ethambutol-susceptible clinical isolates of Mycobacterium tuberculosis from northwestern Russia: implications for genotypic resistance testing. J. Clin. Microbiol. 2002; 40: 3810-3813.

16. Hazbon M.H., Bobadilla del Valle M., Guerrero M.I. et al. Role of embB codon 306 mutations in Mycobacterium tuberculosis revisited: a novel association with broad drug resistance and IS6110 clustering rather than ethambutol resistance. Antimicrob. Agents Chemother. 2005; 49: 3794-3802.

\section{Информация об авторах}

Беспятых Юлия Андреевна - м. н. с. лаборатории молекулярной генетики микроорганизмов НИИ физико-химической медицины ФМБА России; тел.: 8 (909) 961-18-46; e-mail: Juliabespyatykh@gmail.com Шитиков Егор Александрович - науч. сотр. лаборатории молекулярной генетики микроорганизмов НИИ физико-химической медицины ФМБА России; тел.: 8 (916) 835-24-32; e-mail: Eshitikov@mail.ru

Зименков Данила Вадимович - к. б. н., науч. сотр. лаборатории биологических микрочипов ФГБУН "Институт молекулярной биологии им. Энгельгардта" РАН; тел.: (499) 135-98-46; e-mail: z@biochip.ru

Эулагина Елена Валерьевна - науч. сотр. лаборатории биологических микрочипов ФГБУН "Институт молекулярной биологии им. Энгельгардта" РАН; тел.: (499) 135-98-46; e-mail: elenka176@yandex.ru

Грядунов Дмитрий Александрович - к. б. н., ведущий научный сотрудник лаборатории биологических микрочипов ФГБУН "Институт молекулярной биологии им. Энгельгардта" РАН; тел.: (499) 135-98-46; e-mail: grad@biochip.ru

Носова Елена Юрьевна - к. м. н., науч. сотр. Московского городского научно-практического центра борьбы с туберкулезом; тел.: (499) 268-01-31; e-mail:rna68@rambler.ru

Букатина Анастасия Александровна - науч. сотр. Московского городского научно-практического центра борьбы с туберкулезом; тел.: (499) 268-01-31; e-mail: nastec@bk.ru

Шульгина Марина Владимировна - д. б. н., руководитель лаборатории этиологической диагностики Санкт-Петербургского НИИ фтизиопульмонологии; тел.: (812) 579-24-21; e-mail: mshulgina@spbniif.ru

Журавлев Валерий Юрьевич - к. м. н., в. н. с. лаборатории этиологической диагностики Санкт-Петербургский НИИ фтизиопульмонологии; тел.: (812) 579-24-21; e-mail: spbniif_all@mail.ru

Ильина Елена Николаевна - д. б. н., зав. лабораторией молекулярной генетики микроорганизмов НИИ физико-химической медицины ФМБА России; тел.: (499) 245-04-70; e-mail: ilinaen@gmail.com

Поступила 09.07.13 () Коллектив авторов, 2013 УДК 579.873.21.04 